\title{
Compassionate Honesty
}

\author{
Charles L. Loprinzi, M.D., Lidia Schapira, M.D., ${ }^{2}$ Timothy Moynihan, M.D.,' Gregory P. Kalemkerian, M.D., ${ }^{3}$ \\ Charles von Gunten, M.D., Ph.D., ${ }^{4}$ and David Steensma, M.D. ${ }^{1}$
}

\section{Introduction}

$\mathbf{P}$ ATIENTS WITH CANCER COMPRISE $40 \%-100 \%$ of patients seen by those working in hospice and palliative medicine around the world. Consequently, the skills of oncologists in integrating palliative care and making appropriate referrals for hospice care have been a subject of intense interest since the inception of the field. Most are aware that oncologists routinely assist patients in making difficult decisions, at the time of initial cancer diagnosis and for months or years thereafter. Such discussions involve imparting the news of a new diagnosis of cancer or a recurrence, providing results of day-to-day tests or staging scans, and addressing prognosis. Typically, the most difficult discussions are those that address the lack of effective medical treatments. Although they are aware they should do this in a compassionate and sensitive manner, most had no specific training or feedback on how to do this. Yet, these are precisely the issues of most concern to those in hospice and palliative care.

In recognition of these facts, the Journal of Clinical Oncology initiated a series written primarily by and for oncologists that addresses this area. ${ }^{1}$ Called, "The Art of Oncology," the series aimed to publish direct and meaningful reflections to help oncologists in their practices. The Journal of Clinical Oncology is the most high-impact journal serving oncologists in the world; what it publishes is noticed. The readership of the series has been high.

Professionals in palliative medicine will want to know of this series for at least three reasons: (1) it gives insight into how oncologists think about the issues; (2) it gives advice that oncologists have given to oncologists about how to deal with these issues; and (3) each can be used as a way to stimulate discussion with oncologists in your area on which to build better relationships.

\section{Tell the Truth}

Conversations about expectations of recovery, time frames, and hope for a normal future are extremely important for patients with cancer and their loved ones. A common sentiment among many oncology professionals is the need to nurture hope in their patients. Many colleagues are afraid of causing harm by forthrightly addressing issues of prognosis when the outlook is grim. This is only normal, as is the desire to protect patients from harm or disappointment. It is easy to imagine situations where the doctor means well and avoids addressing important issues out of a genuine desire to protect his or her patient. In the article "Setting Goals to Maintain Hope," Von Roenn and von Gunten provide a strategy to direct physicians in their approach to honest, yet hopeful, disclosure of a poor prognosis. Teaching patients to reframe the object of their hope, and setting realistic, short-term goals allow the oncologist to engage in a dialogue that focuses on life, instead of avoiding the topic altogether. "Sign-posting" provides valuable clues to a patient and his loved ones that they have entered into a new and perhaps unfamiliar or frightening territory. As noted by the authors, if a person is driving on a highway, it is appropriate to have warning signs to alert drivers as to when the exit is approaching. In a similar fashion, patients and their loved ones need some warnings from the doctor that signal that a change has occurred or that the end is near.

Smith $^{3}$ provides a clear and logical strategy for helping clarify goals and plans of care in the piece entitled "Tell it Like it is." He advocates the use of a written document in which the doctor and patient record important information about the disease, intention of treatment, and emergency contacts. This straightforward approach can be adapted to other situations and serve as a model for clarity and partnership between patients and their professional caregivers.

"Caring for Dying Patients: What is Right?"4 describes the consequences of the all too familiar situation whereby patients with advanced incurable cancers are not told the truth about their condition. They are sent home "to try to get stronger so that they can become fit enough to receive chemotherapy." The frequent consequence of this scenario is that an ill patient comes back to an emergency department with a life-threatening event. Without the patient and family's appropriate understanding of the situation and possible complications that might occur, they are left to struggle alone without the professional guidance required to sort through difficult treatment choices. This raises one of the central issues of the patient-oncologist relationship, namely to ask and consider if the one and only business of this relationship is the

\footnotetext{
${ }^{1}$ Mayo Clinic, Rochester, Minnesota.

${ }^{2}$ Massachusetts General Hospital, Boston, Massachusetts.

${ }^{3}$ University of Michigan, Ann Arbor, Michigan.

${ }^{4}$ Center for Palliative Studies, San Diego Hospice, San Diego, California.

Accepted July 19, 2010.
} 
choice and application of treatment. To be "fit for chemotherapy" implies that chemotherapy is what the patient is "fighting for." Should chemotherapy be viewed as simply an assistive device to allow life, or as a priority in and of itself? At times, a conversation with a thoughtful oncologist can open up new avenues for relief of symptoms through palliative care, allowing the patient and family to exert more control over future events.

On another practical and perhaps less emotional level, readers can learn from "Treatment Decision Aids" about how to discuss the pros and cons of the use of chemotherapy in the setting of advanced or incurable cancer. ${ }^{5}$ In this article, Leighl discusses how to help patients weigh potential treatment benefits and risks, so that they can be better informed and ready to participate in a shared decision-making process.

Pediatric oncology poses unique challenges for doctors who must communicate with both patients and their parents, and may need to balance and integrate different perspectives. Two pieces focus on compassionate honesty in pediatrics: "The Day One Talk" ${ }^{\prime}$ and "Tell the Children."7 The first article stresses the importance of providing sufficient information and building a respectful and supportive partnership between oncology professionals and families. The authors favor a planned and yet flexible approach from "Day One," cautioning clinicians to take their cues from parents and families and to be as clear and compassionate as possible. They also address the need for the pediatric oncologist to relay information directly to his or her patient, and remind us that well informed children and adolescents can better cope with illness and treatment. The second article, "Tell the Children," explores the difficult topic of informing children that death is imminent. Using two case vignettes, the authors compare and contrast different approaches. In one case, parents forbade doctors and hospice workers from talking about death, both with the dying child and his sibling. In the other, a family invited open communication and included a healthy sibling in the final hours of the dying child's life. The authors' clear message is that developmental theory and research confirms both the importance of honesty and the ability of children to accept death. While honest recognition of a child's approaching death can be unbearably sad, progress in pediatric palliative care now allows patients and their families to receive the coaching, assistance and support they need through end of life and, for families, into the period of bereavement.

\section{Necessary Collusion}

One of the most controversial pieces in the Art of Oncology series is "Necessary Collusion: Prognostic Communication with Advanced Cancer." ${ }^{8}$ Helft, an oncologist and ethicist, argues that since a physician's responsibility is to provide hope for patients, sharing bad news may sometimes interfere with this objective. He suggests that many patients really do not want to hear bad news, despite asking about what is going to happen to them, and argues that patients often want the physician to portray all news in the best possible light, even if it means distorting or withholding certain facts. In a commentary, Kalemkerian" points out that, "The argument made by Helft in favor of 'necessary collusion' in the discussion of prognosis between patients with cancer and their oncologists is predicated on the presumption that the primary goal of oncologic care is to maintain hope. If this were the case, then it would be difficult to argue against such an approach. However, the primary goal of oncologic service is to care for patients with cancer in a comprehensive manner, with appropriate attention paid to their physical, psychological, and practical needs. Helping patients maintain hope is but one part of this, not the core principle." ${ }^{9}$ Oncologists should understand how to have a conversation with patients that encompasses more than hope for cure. This article and its counterpoint reflect conflicting opinions among oncologists both about core professional values, as well as the duty to inform patients, in order to allow them to make informed choices based on an accurate representation of their medical condition.

"Concealment of Information in Clinical Practice: Is Lying Less Stressful than Telling the Truth?" may help explain why physicians do not always provide realistic information to patients. The article presents data from behavioral research that documents the stress experienced by those who tell the truth about poor prognostic information. The authors conclude that it is often easier for physicians to lie to patients than to tell them the truth. ${ }^{10}$

\section{Don't give up on me}

There are patients who want to be treated "aggressively" despite understanding that such treatments may cause more suffering and have little chance of improving quality or length of life. To oncologists, the word aggressive denotes intensive treatments that are almost invariably accompanied by adverse effects and, in the setting of advanced cancer, may well add to the burden of symptoms experienced by the patient. For some, the use of "aggressive treatment" signifies that everything possible was done to offer the patient a chance to extend his survival. In the powerful poem, "Can You Cure Him for the Baby's Sake?," Mehta ${ }^{11}$ describes a patient and his partner who persuade a physician to administer chemotherapy when most would consider such treatment futile. In an accompanying commentary, Fetting ${ }^{12}$ discusses the moral distress that such demands bring on oncologists, other members of the health care team, and society. A variation on this theme is described in "Another Infusion of Hope." This describes an Italian patient who asked not to receive bad prognostic information and wished to continue to receive chemotherapy, leading her physicians and family to administer an intravenous vitamin to her while she was being cared for at home. The patient was told she was receiving chemotherapy, thus boosting her belief that everything possible was being done; it is possible that this understanding helped her to die peacefully at home. While most oncologists would be uncomfortable with this deception, the author's discussion of the situation reflects a thoughtful and compassionate individualized approach concordant with the patient and her family's stated wishes. Those who wish to read more on the protective mechanisms commonly used by patients facing death will appreciate Rouseau's article, "Death Denial," which explicitly addresses the useful role of denial in patients with advanced cancer. ${ }^{13}$

In "But Doctor, What Have I Got to Lose?," Harnett and Moynihan ${ }^{14}$ point out the important trade-offs a patient must consider before trying chemotherapy when the chance of benefit is quite low. If the possibility of response is low, the risks of treatment-related toxicities need to be carefully 
discussed and considered. Such toxicities include premature death, reduced quality of life, and loss of opportunities to accomplish the important tasks that often come in the waning days of one's life, such as planning for physical and psychosocial needs of loved ones. Five specific directives, first proposed by Ira Byock in Dying Well, ${ }^{15}$ are reiterated in this piece, including the need for dying patients to tell their family and loved ones: "Please forgive me for doing those things that I have done to you that were not right, I forgive you for what you might have done to me that was not best, thank you for all that you have done for me, I love you, and goodbye."

\section{How to deliver bad news}

Recognizing the central and recurring theme of breaking sad news to patients, the Art of Oncology features many articles on this subject. They vary considerably in tone and content and include moving narratives and evidence based guidelines for practice. One of the earlier articles in the series, entitled, "Giving Bad News to Cancer Patients: Matching Process and Content," discusses the angst experienced by doctors when giving bad news to patients, especially when it is unexpected, or the patient or family is not ready for it. ${ }^{16}$ The authors provide suggestions to help clinicians understand the task, process components, and deliver information in a compassionate and effective manner.

The SPIKES mnemonic (Setting up the discussion, delineating the patient Perception of the situation, obtaining an Invitation to provide information, providing the Knowledge of the situation, assessing patient Emotions, and Summarizing the discussion while Setting goals) was introduced by Bruckman and colleagues ${ }^{17}$ to outline a method of delivering bad news. "Discussing Bad News in the Outpatient Oncology Clinic: Rethinking Current Communication Guidelines" further elaborates on the topic and identifies three additional aspects of these discussions as they occur in real life. ${ }^{18}$ First, that physicians are often not able to plan ahead of time for all "bad news" interactions because many times, there is no advanced warning that bad news needs to be delivered. Bad news may be a part of almost any outpatient or inpatient oncology encounter, which may not allow an opportunity to set up a bad news discussion with a dedicated room, extended time, or all patient-desired family members present. Second, bad news interactions often do not focus on one central piece of information, but rather involve multiple aspects. Finally, bad news interactions are rarely dyadic-more frequently they involve a clinician, patient, and at least one relative or loved one. Clinicians need to know how to acknowledge the patient and family together and, with the patient's consent, to balance each person's specific needs for information, attention and support.

An early piece in the Art of Oncology series addresses the frequently asked question, "Doc, How Much Time Do I Have?," by describing a role play in which experienced physicians were asked to address this question in a simulated clinical encounter. ${ }^{19}$ The physicians' responses were videotaped and transcribed, portraying the different ways that experienced clinicians respond to this question. This piece led to a subsequent article in which Schapira and colleagues ${ }^{20}$ argue that this question should be addressed with another direct question back to the patient asking them why they wish to know this information. By exploring the patient's concerns and fears and addressing them explicitly, conversations with patients can be greatly enriched.

One of the more popular articles in the Art of Oncology series is "Just Say Die."."1 The use of indirect language and euphemism, such as "end of life", and the avoidance of the words "die" and "death" are all too common in our verbal communications and published literature. In making his point, the author asks if doctors should talk about "beginning of life care," instead of "infant care."

The "Power of Silence" discusses the usefulness of allowing silence when giving patients bad news. ${ }^{22}$ This piece recounts a situation in which the physician team sat in silence with a patient and family for a prolonged time- $30-40$ minutes. For many of us, even 30 seconds may feel like a century and a minute or two requires focus and discipline; in the right setting, however, silence can have a marked therapeutic effect.

"The Sentinel" was written by an otolaryngologist who describes a patient with anaplastic thyroid cancer. ${ }^{23}$ When the patient asked his physician, "What will kill me? What will happen?," the physician had difficulty responding; he found himself unable to tell the patient that he might exsanguinate from an acute carotid artery rupture. A commentary on this article entitled "Missed Opportunities," by Moynihan and von Gunten, ${ }^{24}$ reminds us that the situation described in "The Sentinel" demanded a resolution. If the specialist was unable to answer the patient's questions, then perhaps a palliative care team could have helped. To this end, it is not necessary for one cancer specialist to provide all services, as long as he or she delegates important aspects to other colleagues and together they function as a multidisciplinary team assembled to meet all of the patient's needs.

The Art of Oncology series includes several articles that address the difficulties posed by discussions of resuscitation preferences and hospice referrals. Both of these topics require ample use of direct, but compassionate, honesty, as noted by von Gunten in two separate articles. ${ }^{25,26}$ Another perspective regarding the consequences of failing to discuss such issues is offered in, "Overcoming Obstacles to Hospice and Palliative Care: An Ethical Examination of Inertia and Inaction." 27

Practical suggestions for teaching and improving communication skills are provided by Back and colleagues in four articles in this series. The authors initially describe their use of role play to teach communication skills to medical oncology fellows. ${ }^{28}$ Subsequently, they provide practical tips for discussing prognosis with patients, both those who are prepared to engage in such discussions ${ }^{29}$ and those who are reluctant to initiate or participate in these conversations. ${ }^{30}$ Finally, this group recently published an article describing a method for teaching oncologists how to train oncology fellows to have better communication skills, by using role play situations. ${ }^{31}$

Testimonials written by oncology fellows have also been published in this section, providing insights into the training and experience of junior specialists. ${ }^{32,33}$ Perspectives from oncologists-in-training enrich our collective experience as a community of multigenerational professionals, and remind us of the hard work involved in climbing the steepest part of our professional "learning curve."

\section{Please do not give me (Us) bad news}

How should oncologists respond to a request to withhold information? "Truth or Consequences, What to do When your 
Patient Doesn't Want to Know" deals with this important scenario by addressing the consequences of denial for the patient, the family, and the health care professionals involved. ${ }^{34}$ It begins with a powerful description of a clinical case, written by a medical student as she grapples with these issues. Her story ends with the unsuccessful resuscitation of a young woman with advanced cancer. The author's own reaction and feelings, as well as those of her supervisors, serve as a reminder of the impact of futile resuscitation attempts and the attendant moral distress for all involved. The related topic of what happens when a family member tells the doctor to withhold information from the patient is addressed in "A Request for Nondisclosure: Don't Tell Mother." ${ }^{\prime 35}$ This issue poses ethical dilemmas, particularly in the United States, where legal and cultural forces favor complete disclosure and mandate that patients be given informed consent for treatment.

A candid and inspiring piece, "Surprised by Hope," discusses a situation in which a patient specifically told her oncologist, after she had received a realistic assessment about her cancer and treatment options, that she wanted her oncologist to be more optimistic about her case. ${ }^{36}$ This patient, appropriately informed, "had her eyes wide open, but preferred to wear rose-colored glasses." The doctor responded by avoiding confrontation and honoring her patient's clear request.

\section{How giving bad news affects the oncologist}

Oncology professionals are personally affected by caring for patients on a daily basis with life-threatening illnesses who face loss, disability and death. In "The Narrow Path," Steensma ${ }^{37}$ illustrates the fine line that physicians need to walk in order to remain emotionally close to their patients while still maintaining a safe distance from their suffering. He also describes the serious consequences of falling off to either side of this narrow path.

"Fellow Suffering" was written by an oncology fellow in New York City at the time of the $9 / 11$ terrorist attacks. ${ }^{38}$ The author notes that she was not affected as much by this tragedy as she might have expected, because she had already seen such extensive human suffering and so many tragic consequences during her months on the oncology wards. The author also relates that fellows can provide mutual support and advice by more openly discussing their experiences with each other.

\section{Concluding Remarks}

There are advantages to both the patient and physician to being honest and forthright, even if the truth is disappointing or frightening. Honest communication of clinical reality allows patients to make better informed decisions regarding treatment options, fully prepare for eventualities, have worthwhile discussions with loved ones, and not miss opportunities to do whatever is important to them with their remaining time. There are patients who may not welcome such openness, but most do appreciate knowing what lies ahead. Learning how to impart such information in a sensitive and compassionate manner requires not only good intentions, but strong communication skills (that we now know can be taught) and the discipline to do what will serve the patient best, rather than what is easiest or feels good. By providing stories of personal reflection as well as guidelines and practical advice, Art of Oncology promotes lifelong learning which enhances the practice of oncology for both our patients and ourselves.

\section{Author Disclosure Statement}

No competing financial interests exist.

\section{References}

1. Loprinzi C, Canellos GP: The art of oncology-When the tumor is not the target. I Clin Oncol 2000;18:3.

2. Von Roenn JH, von Gunten CF: Setting goals to maintain hope. J Clin Oncol 2003;21:570-574.

3. Smith TJ: The art of oncology: When the tumor is not the target. Tell it like it is. J Clin Oncol 2000;18:3441-3445.

4. Bretscher M: Caring for dying patients: What is right? J Clin Oncol 2000;18:233-234.

5. Leighl NB, Butow PN, Tattersall MH: Treatment decision aids in advanced cancer: When the goal is not cure and the answer is not clear. J Clin Oncol 2004;22:1759-1762.

6. Mack JW, Grier HE: The day one talk. I Clin Oncol 2004;22:563-566.

7. Hilden JM, Watterson J, Chrastek J: Tell the children. J Clin Oncol 2000;18:3193-3195.

8. Helft PR: Necessary collusion: Prognostic communication with advanced cancer patients. I Clin Oncol 2005;23:31463150.

9. Kalemkerian GP: Is collusion necessary? A commentary on necessary collusion. J Clin Oncol 2005;23:3153-154.

10. Panagopoulou E, Mintziori G, Montgomery A, Montgomery A, Kapoukranidou D, Benos A: Concealment of information in clinical practice: Is lying less stressful than telling the truth? J Clin Oncol 2008;26:1175-1177.

11. Mehta P, Fetting J: Can you cure him, for the baby's sake? J Clin Oncol 2003;21:4064-4065.

12. Giorgi F, Bascioni R: Another infusion of Hope. J Clin Oncol 2009;27:1722-1723.

13. Rousseau P: Death denial. J Clin Oncol 2000;18:3998-3999.

14. Harnett PR, Moynihan TJ: "But doctor, what have i got to lose...?" J Clin Oncol 2001;19:3294-3296.

15. Byock I: Dying Well: The Prospect for Growth at the End of Life. East Rutherford NJ: Putnam-Riverhead, 1997

16. Baile WF, Beale EA: Giving bad news to cancer patients: Matching process and content. J Clin Oncol 2001;19:25752577.

17. Baile WF, Buckman R, Lenzi R, Lenzi R, Glober G, Beale EA, Kudelka AP: SPIKES-A six-step protocol for delivering bad news: Application to the patient with cancer. Oncologist 2000;5:302-311.

18. Eggly S, Penner L, Albrecht TL, Cline RJ, Foster T, Naughton M, Peterson A, Ruckdeschel JC: Discussing bad news in the outpatient oncology clinic: Rethinking current communication guidelines. J Clin Oncol 2006;24:716-719.

19. Loprinzi CL, Johnson ME, Steer G: Doc, how much time do I have? J Clin Oncol 2000;18:699-701.

20. Schapira L, Eisenberg PD, MacDonald N, Mumber MP, Loprinzi C: A revisitation of "Doc, how much time do I have?" I Clin Oncol 2000;18:2640-2643.

21. Berry SR: Just say die. J Clin Oncol 2008;26:157-159.

22. Himelstein BP, Jackson NL, Pegram L: The power of silence. J Clin Oncol 2001;19:3996.

23. Campbell BH: The sentinel. J Clin Oncol 2008;26:17601761. 
24. Moynihan TJ, von Gunten CF: Missed opportunities: Commentary on "The sentinel." J Clin Oncol 2008;26:1762-1763.

25. von Gunten CF: Discussing do-not-resuscitate status. J Clin Oncol 2001;19:1576-1581.

26. von Gunten CF: Discussing hospice care. I Clin Oncol 2002;20:1419-1424.

27. Daugherty CK, Steensma DP: Overcoming obstacles to hospice care: An ethical examination of inertia and inaction. J Clin Oncol 2002;20:2752-2755.

28. Back AL, Arnold RM, Tulsky JA, Baile WF, Fryer-Edwards KA: Teaching communication skills to medical oncology fellows. J Clin Oncol 2003;21:2433-2436.

29. Back AL, Arnold RM: Discussing prognosis: "How much do you want to know?" talking to patients who are prepared for explicit information. J Clin Oncol 2006;24:4209-4213.

30. Back AL, Arnold RM: Discussing prognosis: "How much do you want to know?" talking to patients who do not want information or who are ambivalent. I Clin Oncol 2006;24: 4214-4217.

31. Back AL, Arnold RM, Baile WF, Tulsky JA, Barley GE, Pea RD, Fryer-Edwards KA: Faculty development to change the paradigm of communication skills teaching in oncology. I Clin Oncol 2009;27:1137-1141.
32. Francis LK: Learning to listen: A fellow's experience. J Clin Oncol 2006;24:3209-3210.

33. Arnold SJ, Koczwara B: Breaking bad news: learning through experience. J Clin Oncol 2006;24:5098-5100.

34. Neff P, Lyckholm L, Smith T: Truth or consequences: What to do when the patient doesn't want to know. J Clin Oncol 2002;20:3035-3037.

35. Hallenbeck J, Arnold R: A request for nondisclosure: Don't tell mother. J Clin Oncol 2007;25:5030-5034.

36. Francis PA: Surprised by hope. J Clin Oncol 2008;26:60016012.

37. Steensma DP: The narrow path. I Clin Oncol 2001;19:21022105.

38. Armstrong J: Fellow suffering. J Clin Oncol 2004;22:44254427.

Address correspondence to: Charles L. Loprinzi, M.D. Mayo Clinic 200 First Street S.W. Rochester, MN 55905

E-mail: cloprinzi@mayo.edu 

This article has been cited by:

1. Charles F. von Gunten . 2010. Reaching OutReaching Out. Journal of Palliative Medicine 13:10, 1177-1177. [Citation] [Full Text] [PDF] [PDF Plus] 